\title{
Article \\ On the Tidal Prism: The Roles of Basin Extension, Bottom Friction and Inlet Cross-Section
}

\author{
Marco Petti, Sara Pascolo *, Silvia Bosa (D) and Nadia Busetto \\ Dipartimento Politecnico di Ingegneria e Architettura, University of Udine, 33100 Udine, Italy; \\ marco.petti@uniud.it (M.P.); silvia.bosa@uniud.it (S.B.); nadia.busetto@uniud.it (N.B.) \\ * Correspondence: sara.pascolo@uniud.it; Tel.: +39-0432-558713
}

check for

updates

Citation: Petti, M.; Pascolo, S.; Bosa, S.; Busetto, N. On the Tidal Prism: The Roles of Basin Extension, Bottom Friction and Inlet Cross-Section. J. Mar. Sci. Eng. 2021, 9, 88. https:// doi.org/10.3390/jmse9010088

Academic Editor: Yeon S. Chang

Received: 22 December 2020

Accepted: 11 January 2021

Published: 15 January 2021

Publisher's Note: MDPI stays neutral with regard to jurisdictional claims in published maps and institutional affiliations.

Copyright: (C) 2021 by the authors. Licensee MDPI, Basel, Switzerland. This article is an open access article distributed under the terms and conditions of the Creative Commons Attribution (CC BY) license (https:// creativecommons.org/licenses/by/ $4.0 /)$.

\begin{abstract}
The prism of the Lignano tidal inlet was approximately constant over the last forty years, although the section width has halved. This has led to questions concerning the factors that most influence the tidal prism, and on the applicability of the well-known $A-P$ relationship. A conceptual scheme of the sea-channel-lagoon system has been used to perform a sensitivity analysis of different parameters that characterize both the basin and the inlet cross-section. A 2D hydrodynamic model has been applied to evaluate the prism and compare it to the one derived by a static method, which is the basis of the analytical derivation of the $A-P$ linkage. Three regimes have been found in the prism variability as a function of the basin extension: a linear static regime between prism and basin area; an asymptotic regime in which the prism depends only on the basin bottom friction; and an intermediate one. In addition, the roles of the inlet and channel sizes on the prism value have been investigated. The results, compared to the empirical relationships between the prism and the inlet cross-section, show that a variation in the cross-sectional area does not always corresponds to a change in tidal prism.
\end{abstract}

Keywords: tidal prism; tidal inlet; equilibrium cross-section; $A-P$ relationship; back-barrier basin; bottom friction

\section{Introduction}

Coastal lagoons are highly dynamic and complex transitional environments that form after a sheltered basin is flooded by the sea and one or more openings (i.e., tidal inlets) allow a continuous water exchange with the sea during each tidal cycle [1]. Flood and ebb currents alternately originate from the gradient of the surface elevation between the sea and the inner lagoon, thereby governing all the hydrodynamic behavior. Furthermore, tidal inlets are fundamental in the morphodynamic processes of the nearby coast and of the lagoon itself. In fact, they act as both sources and sinks of the sediments which are suspended from the bottom by the wave motion, which is locally generated inside the basin or outside in the open sea [2-10]. Sediments are then transported by currents that transfer the material into the network of tidal channels or along the shore in the surf zone. The competing effects of waves and tides that attempt to close and widen the inlet, respectively [11,12], shape the morphology of the channel entering the lagoon. In this sense, the net exchange of sediments between the tidal basin and the sea largely affects the cross-sectional form of the tidal inlet, which adapts to dominant hydrodynamic and sediment transport conditions in the medium-long term (i.e., on the timescale of years or decades) [13].

Barrier coasts and tidal inlets are also important for their ecological, economic and touristic roles, as they are intensely used by human activities linked to different productive systems [14]. In many cases, tidal channels connect the open sea with harbor sites located behind the back-barrier, increasing the socio-economical value of these natural connections. For this reason, they are often required to be wide and deep and morphologically stable enough to allow navigation [15]; this condition sometimes involves the building of marine 
structures to protect the port and stabilize the inlet cross-section. The inlet shape can in turn directly affect the hydrodynamic field in the enclosed basin in terms of current velocities and tidal level amplitudes, and therefore sediment transport.

This is the case for the Lignano tidal inlet, one of the six inlets of the Marano and Grado lagoon, in the northern Adriatic Sea in Italy, which has undergone important morphological changes over the last four decades $[4,16]$. The construction of the protective pier of Marina Punta Faro located on the internal side of the Lignano inlet resulted in a narrowing of the inlet itself. A sand deposit on the outer side of the pier has progressively increased over time, leading to a reduction of the inlet width of about $55 \%$ compared to the initial stable morphology. Petti et al. [16] explored this trend in depth by means of an integrated approach based on morphodynamic modeling, and the results and the historical reconstruction of the shifting of the coastline confirm that the current crosssection is reaching a new stable condition. In particular, it has been shown that the tidal prism referring to the current configuration is very similar to the one estimated before the natural shape of the Lignano inlet was altered. This means that the water volume currently exchanged through the inlet with the open sea during a half characteristic tidal cycle is approximately the same as the previous one in the ante-operam configuration, despite the important morphological changes that have occurred.

Ebb and flood discharges in the inlet channel strongly influence the tidal prism [17], thereby playing an important role from both environmental and ecological points of view [18]. The tidal prism has a significant effect on the morphodynamic processes that involve the tidal basin portion behind the back-barrier and the ebb tidal delta on the sea side [19]. In natural conditions, the size of the inlet cross-section tends towards an equilibrium shape determined by the balance between the transporting ebb tidal capacity of the entrance flow and the longshore transport [11,13]. O'Brien [20,21] and Jarrett [22] first investigated the relationship between the gorge cross-sectional area and a characteristic gorge flow parameter from both empirical and analytical points of view. The result was the well-known equation $A-P$, which provides the minimum cross-sectional area $A$ of the tidal inlet that is morphologically stable for the assigned tidal prism $P[12,13,23-33]$.

The validity of this law has been emphasized by much empirical evidence gathered from a large number of tidal inlets, both with and without jetties, located along the North American and European coasts. Fontolan et al. [34] studied the sediment storage at tidal inlets in northern Adriatic lagoons, and they proposed a relationship of the O'Brien type, using data only from the inlets of the Venice lagoon and the Marano and Grado lagoon. However, in the case of the Lignano tidal inlet, both the cross-section of the ante-operam configuration and the current one respectively, can be considered morphologically stable, even if they are associated with the same prism, and their areas differ by about 20-30\% [16]. This condition seems to disagree with the above relationship, which suggests a single stable area value given the tidal prism.

Marchi [35] proposed a theoretical treatment providing a comprehensive framework in which the previous experimental and analytical models can be rationally set; in light of this, the $A-P$ equation can be referred to as O'Brien-Jarrett-Marchi's law [19]. This power law has been derived by means of an idealized representation of the sea-channel-lagoon system and a static propagation scheme that assumes an instantaneous, uniform value of the free surface elevation anywhere within the lagoon. In particular, only localized and distributed energy losses along the tidal inlet channel have been represented, thereby excluding the effects of the flow propagation within the basin. In this sense, the equation takes into account hydrodynamic factors that strictly concern the channel, such as the width, the critical friction velocity for sediment erosion and the flow resistance inside it. On the contrary, parameters regarding the inner tidal basin, among them the size of the basin and the flow resistance due to bottom friction dissipations over tidal flats, are not considered. In a recent study, Reef et al. [36] tried to better explain how tidal inlets can be affected by variations in the lagoon basin geometry, by specifically investigating the role of 
the internal bottom friction and the ratio between the cross-shore width of the lagoon and the tidal wavelength.

The present paper is a first attempt to further investigate the relationship between the tidal prism and the inlet cross-section while taking into account the physical factors concerning both the tidal inlet and the lagoon basin. In particular, some questions are posed: whether and how this relationship may have changed in the case of the Lignano tidal inlet and when a cross-sectional variation can induce a modification in the prism value. The study was performed by means of an idealized geometry which was inspired by the real cases of inlet and lagoon sizes of the northern Adriatic Sea. A two-dimensional (2D) hydrodynamic model, based on the classic shallow water equations was applied in order to perform a sensitivity analysis by varying different parameters and evaluating their effects on the tidal prism value. The results obtained with the simplified model were then compared to those derived both from a one-dimensional (1D) static model and a 2D complete numerical application based on a computational mesh representing a real domain.

The arrangement of the paper is as follows: Section 2 has a brief description of the O'Brien-Jarrett-Marchi law; Section 3 describes the numerical setup; Section 4 shows the results obtained, followed by the discussion of the comparisons and the main considerations on the issues raised above.

\section{On the Tidal Prism-Cross-Section Relation}

Tidal prism is defined as the total volume of water which flows through the inlet between low water level and the following high water level, i.e., during flood. In the absence of any significant fresh water flow into the tidal basin, an equal volume of water is exchanged during ebb [17]. As a first approximation, tidal prism can be estimated as indicated in Equation (1) [32,35,37]:

$$
P=2 a_{t} S_{b}
$$

$a_{\mathrm{t}}$ being the tidal amplitude at the inner side of the tidal channel and $S_{b}$ the basin surface area, which coincides with the overall lagoon in the case of a single tidal inlet or with the sub-basin afferent to the outlet of the channel network in a multiple inlet system [37]. This equation neglects propagation effects, as if the propagation of the tide inside the basin could be assumed as almost instantaneous. This means that instant by instant, the surface elevation is the same in all points of the lagoon basin $S_{b}$, regardless of its extension.

Marchi [35] introduced a reduction coefficient to the right-hand side of Equation (1) to account for the differences between the water levels due to the delay of tide in the internal points compared to those at the inlet, while the effects of the bottom friction dissipation have been neglected. The author referred to an idealized scheme of a semicircular bay with radius $r_{0}$ connected to the sea with a straight rectangular inlet channel [19]; based on this simplified geometry, the reduction coefficient $\varphi$ was derived by integrating the variation of the surface elevation as a function of the distance between the internal points and the lagoon inlet, thereby finding the final expression given by Equation (2):

$$
\varphi=\left(\frac{2 c_{l}^{2}}{\omega^{2} r_{0}^{2}}\right)\left[\cos \left(\frac{\omega r_{0}}{c_{l}}\right)+\left(\frac{\omega r_{0}}{c_{l}}\right) \sin \left(\frac{\omega r_{0}}{c_{l}}\right)-1\right]
$$

where $\omega$ is the single wave frequency of the tide assumed as a sinusoidal oscillation $[28,38]$, and $c_{l}$ is the relative propagation velocity inside the lagoon.

The reduction coefficient can be considered a scale parameter that allows one to solve a complex problem by means of a simple static model; it only takes into account the effects of the propagation within the inlet channel and that assumes a uniform value of tidal level throughout the basin. In this sense, a 1D approach can be used instead of a more complex 2D model capable of reproducing hydrodynamic processes in the horizontal plane. The value of the coefficient is less than one and it tends to be one when the basin size is small compared to the tidal wavelength. Many authors have chosen 
Equation (1) to estimate the tidal prism, even if the limits of its applicability have not been well quantified $[32,35,37,39,40]$.

Therefore, the tidal prism can deviate from this approximate value for several reasons, often related to the propagation effects that become more evident in the larger basins that show strong deformation of the tidal wave [41]. Moreover, man-made interventions can cause variations in the tidal prism, for example dredging the tidal channels which are essential to navigation, infilling or embanking salt-marshes or stabilizing the inlets with jetties [19]. These changes induce hydrodynamic adjustments to the flow and sediment transport over different time scales, determining morphologically important effects also in the medium-long term [42].

The relationship between the tidal prism and the minimum cross-sectional area $A$ of a stable tidal inlet has been long recognized expressed as the dimensionally nonhomogeneous Equation (3):

$$
A=k P^{\alpha},
$$

where the coefficient $k$ and the exponent $\alpha$ are empirically determined by plotting different values of the area $A$ versus the spring tidal prism $P$ of both natural and stabilized inlets $[12,13,20-22,33,34,37,43]$. In particular, $\alpha$ is a scaling factor belonging to the relatively limited range 0.85-1.10; however, even a small variation in its value can lead to very different areas of the stable cross-section for an assigned tidal prism. By reviewing the main theoretical approaches, Stive et al. [44] found that the exponent should be greater than 1, but the empirical findings do not clearly support this. The discrepancy can be attributed to the implicit errors that can be made in the procedures adopted for estimating the geometry of the section, and above all, the tidal prism. On the contrary, the coefficient $k$ can vary even by a few orders of magnitude, depending on the hydrodynamic and sedimentologic conditions of the specific site, and on the possible presence of jetties [19,32,41].

Equation (3) couples hydrodynamic and morphodynamic processes, since it can be theoretically derived by combining the momentum equation and a dynamic equilibrium condition between the erosive capacity of the current in the tidal inlet and the bed resistance. This equilibrium is reached when the maximum current velocity leads to a bottom shear stress at most equal to the threshold value for incipient sediment motion. Krishnamurthy [27] assumed a logarithmic profile of the current velocity on the vertical plane, a rectangular cross-section and a sinusoidal tidal forcing. Under a similar hypothesis, Marchi [35] applied the 1D momentum balance equation to the inlet channel, assuming that the maximum instantaneous difference between tidal levels at the beginning and the end of the channel corresponds to the maximum velocity current. Kraus [45] considered a balance between the transporting capability of the tidal flow at the inlet and the longshore sediment transport tending to infill the channel. Hughes [32] computed the discharge flowing through the inlet applying the mass balance to the entire tidal basin. All these analytical approaches confirm the power law of Equation (3) and show common features regarding the dependence of the coefficient $k$ on some hydrodynamic parameters. In particular, it can be expressed as a function of the tidal period, the width of the inlet channel, the flow conductance and the maximum bottom shear stress within the inlet.

Table 1 shows some numerical values of the parameters $\alpha$ and $k$ determined for the $A-P$ Equation (3), which are considered in the present paper for comparisons with the results obtained in the Lignano tidal inlet case study. Additionally, the analytical expressions derived for the coefficient $k$ in the theoretical approaches of Marchi [35] and Hughes [32] are reported, $B$ being the inlet width, $T$ the tidal period, $k_{s}$ the channel Gauckler-Strickler parameter, $\tau_{c}$ the bottom critical shear stress for the erosion of the sediments, $\rho$ the water density, $\rho_{s}$ the mass sediment density, $d_{s}$ the median grain-size diameter and $g$ the gravity acceleration. 
Table 1. Empirical and analytical expressions for the $A-P$ relationship in metric units.

\begin{tabular}{|c|c|c|c|c|}
\hline Authors & Notes & Exponent $\alpha$ & & Coefficient $k$ \\
\hline $\begin{array}{l}\text { O'Brien }[20,21] \\
\text { Jarrett }[22]\end{array}$ & $\begin{array}{l}\text { natural inlets } \\
\text { all inlets }\end{array}$ & $\begin{array}{l}1.00 \\
0.95\end{array}$ & & $\begin{array}{c}0.656 \times 10^{-4} \\
1.58 \times 10^{-4}\end{array}$ \\
\hline Marchi [35] & - & 0.857 & & $\left.\pi \sqrt{g} \times \frac{B^{1 / 6}}{\sqrt{\tau_{c} / \rho} \times T \times k_{s}}\right]^{6 / 7}$ \\
\hline $\begin{array}{l}\text { Hughes [32] } \\
\text { Fontolan [34] }\end{array}$ & northern Adriatic Sea & $\begin{array}{l}0.889 \\
0.7439\end{array}$ & 0.87 & {$\left[\frac{B^{1 / 8}}{\sqrt{g\left(\rho_{s} / \rho-1\right)} \times T \times d_{s}^{3 / 8}}\right]$} \\
\hline
\end{tabular}

Equation (3) suggests that the tidal prism should not change if the tidal inlet is in a stable condition-that is, if its cross-section area does not substantially change over time. The morphological evolution of the Lignano inlet has highlighted that the tidal prism remained the same even though the cross-section deeply changed. In this regard, the present study aims to investigate how it is possible to have different values of areas corresponding to stable conditions for the same prism and what the conditions are under which an inlet section variation can lead to a variation of the prism.

\section{Study Site and Numerical Setup}

Lignano tidal inlet is the westernmost of the six inlets that divide a series of barrier islands separating the Marano and Grado lagoon from the Adriatic Sea, in the northern part of Italy, as depicted in Figure 1. This lagoon is very similar to the nearby Venice lagoon in both sedimentological and hydrodynamical terms. All three of the Venice lagoon inlets are characterized by the presence of two jetties, and their role in the morphological evolution of the lagoon itself has been examined in depth $[15,41,46-48]$.

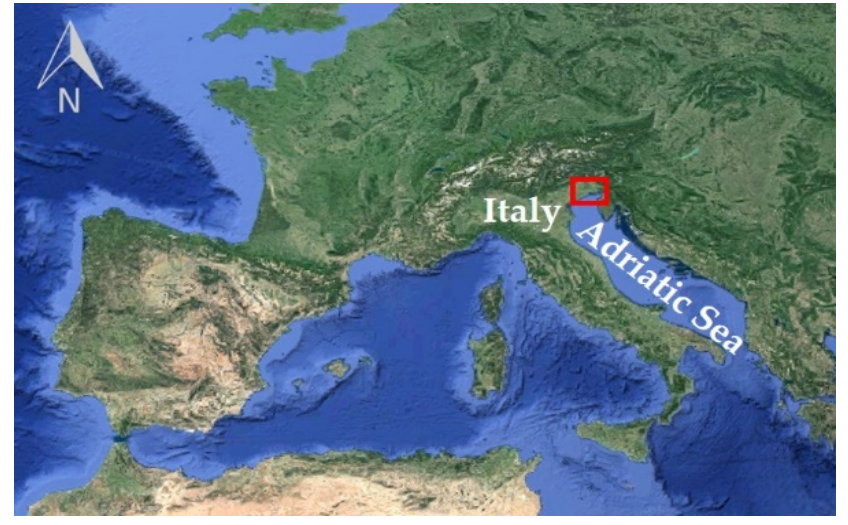

(a)

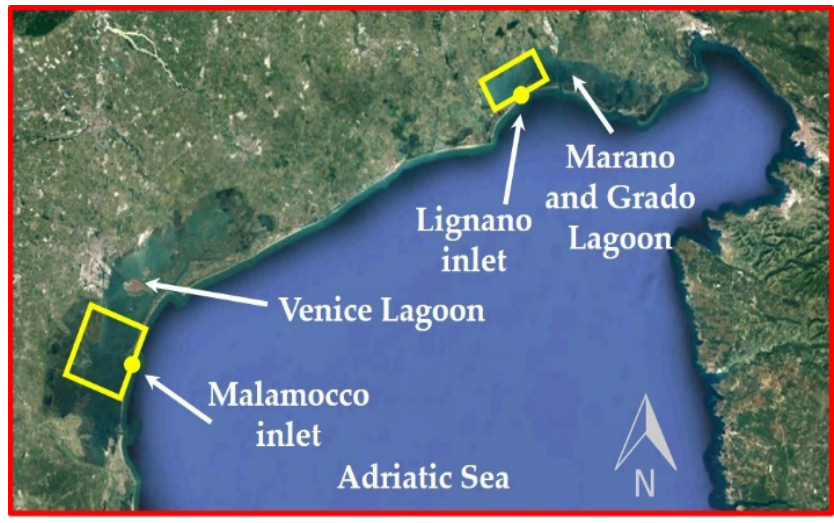

(b)

Figure 1. Marano and Grado Lagoon and Venice Lagoon shown (a) in the European context and (b) in North East Italy, where the schematic basins of the Lignano and Malamocco inlets are also highlighted.

Similarly, the flattening trend of the Marano and Grado lagoon and the silting of its tidal channels have been the focus of recent morphodynamic studies [49,50], along with the progressive narrowing tendency undergone by the Lignano inlet after the construction of the Marina Punta Faro port, as depicted in Figure $2[5,16]$. The bathymetric features of the cross-section of Lignano tidal inlet are known from the surveys carried out by Dorigo [51] in the ante-operam configuration and from more recent datasets used to define the current bed elevations as in Petti et al. [16]. As shown in the graph in Figure 2b, the inlet section area has decreased by approximately $30 \%$ over the past four decades due to the sand deposit that has formed on the outside of the harbor protective pier. 


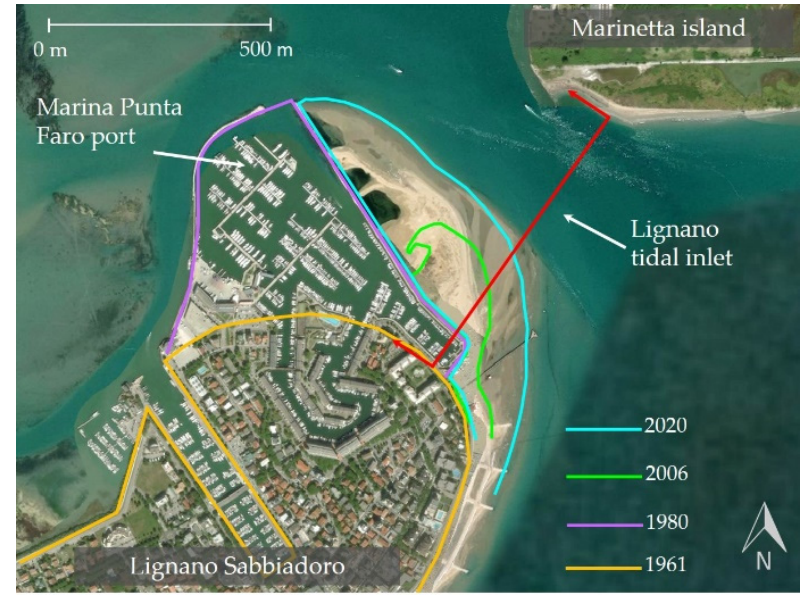

(a)

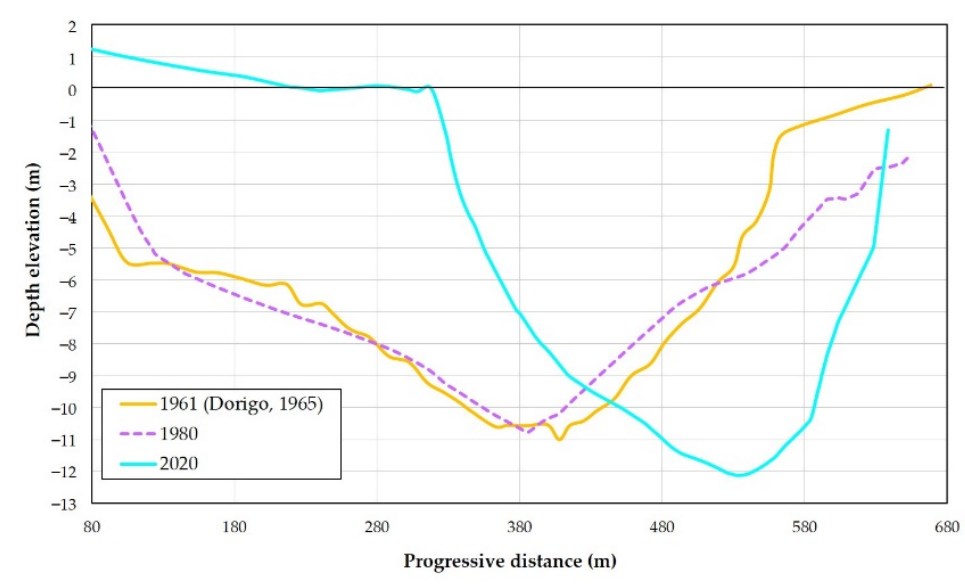

(b)

Figure 2. Historical reconstruction of the narrowing tendency of the cross-section of the Lignano inlet (a) from 1961 to 2020 , and (b) the comparison between the profiles available in 1961 from Dorigo [52] (yellow continuous line), the one in the 1980s after the construction of the pier (purple dashed line) and that in the current configuration (light blue continuous line).

An idealized model of the sea-channel-lagoon system has been realized; it is similar to what other authors have proposed $[15,35,36]$. This scheme can be a useful tool to investigate whether and how the $A-P$ relationship for the Lignano inlet has been changed and to analyze the parameters that most affect the tidal prism value. The domain, depicted in Figure 3, consists of two rectangles, representing the lagoon basin and the open sea respectively, connected to each other by a trapezoidal straight channel. In particular, the geometric and morphological characteristics of the Lignano sub-basin [49] have been taken as a reference for a basic configuration in a first set of simulations.

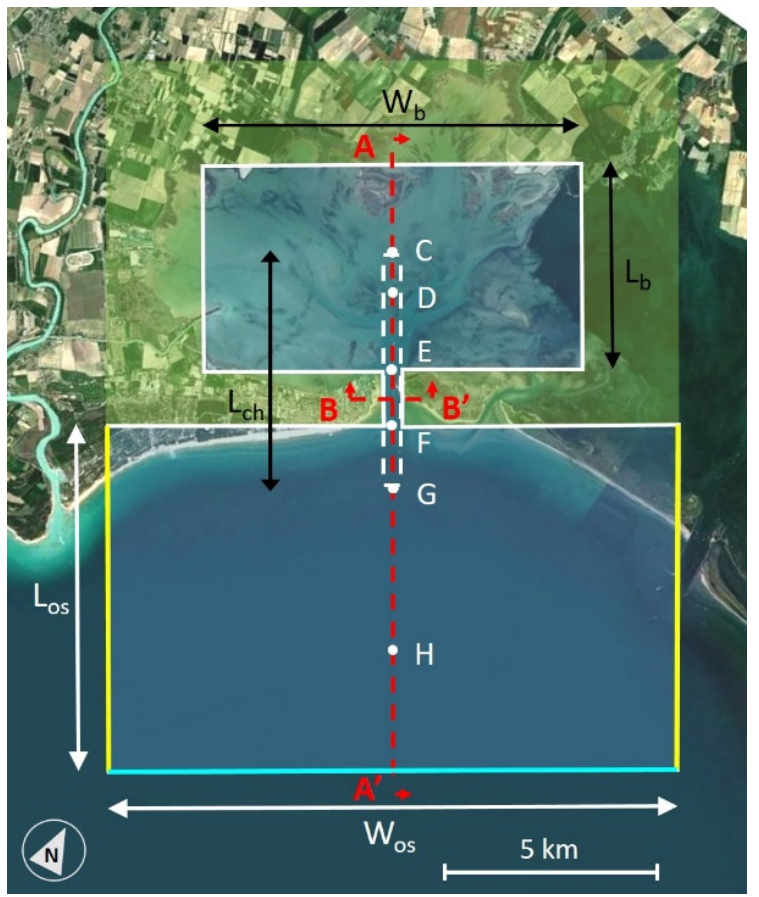

(a)
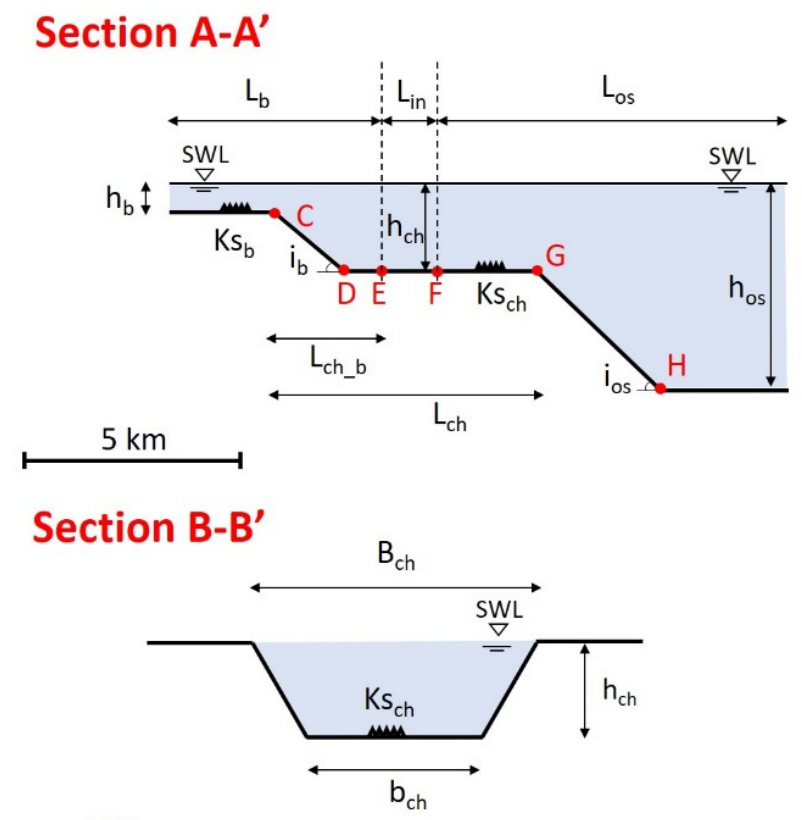

$250 \mathrm{~m}$

(b)

Figure 3. Idealized model of (a) the sea-channel-lagoon system and (b) the longitudinal and cross-sections of the entire domain $\left(A-A^{\prime}\right)$ and of the channel $\left(B-B^{\prime}\right)$, in which the main geometric features are reported. 
The open sea rectangle has a bed slope $\left(i_{o s}\right)$ of $1 / 100$, a typical value of the nearshore of the North Adriatic Sea, until a depth of $40 \mathrm{~m}$ is reached, and then it remains constant. The inlet connecting the two rectangles is $250 \mathrm{~m}$ long $\left(L_{i n}\right), 300 \mathrm{~m}$ wide on the top $\left(B_{c h}\right)$ and $7 \mathrm{~m}$ being the channel depth $\left(h_{c h}\right)$, the latter obtained as an average value from the real longitudinal profile of the Lignano channel. In the simplified scheme, this single main channel enters in the lagoon basin for about $2.4 \mathrm{~km}$ without ramifications, and it has an overall length $L_{c h}$ of about $4 \mathrm{~km}$. The lagoon extension is $50 \mathrm{~km}^{2}$, with a longitudinal width $W_{b}$ of $10 \mathrm{~km}$, a transversal length $L_{b}$ of $5 \mathrm{~km}$, and a uniform depth $h_{b}$ of $1.2 \mathrm{~m}$, which is the average depth of the Lignano sub-basin.

The domain has been discretized with about 100,000 regular cells with sides ranging from 10 to $200 \mathrm{~m}$, where the smaller elements have been used to represent the inlet and the tidal channel, in order to ensure a high resolution of the hydrodynamic field where it has the greatest variability.

As a first step, the simulations have been performed taking into account only the tide as external forcing, hence without considering the effects of wind waves and sediment transport. Both a 1D and a 2DH (two-dimensional horizontal) hydrodynamic models have been applied. The former is based on mass and momentum balances referring to the inlet channel as proposed by Marchi [35] and reported by D'Alpaos et al. [19]. The equations have been discretized with finite difference technique.

The 2DH model solves the classic shallow water equations and it has been successfully applied to study the water levels and current velocities inside the lagoon basin and in the surf-zone of the north-eastern Adriatic coast [16,50,53]. The numerical integration is carried out by means of a well-balanced first order accurate finite volume method, based on Harten-Lax-van Leer-Contact (HLLC) Riemann solver and on a variable reconstruction that satisfies the C-property. Turbulent fluxes are evaluated by means of a Smagorinsky approach and a finite difference scheme. Time integration follows a first order accurate Strang splitting method. More details and references are given in Petti et al. [50]. The model requires that the computational domain is structured, i.e., subdivided into regular or quadrangular cells.

Tidal level oscillations have been represented by a single harmonic component, with a period of $12 \mathrm{~h}$ and an amplitude equal to $\pm 0.40 \mathrm{~m}$. This value corresponds to the average astronomical tidal range in the northern Adriatic Sea, as reported by Dorigo [52] and confirmed by a zero-crossing analysis of tide gauges measurements carried out in the Marano and Grado lagoon [50].

Considering that in the Adriatic Sea the tide moves counter-clockwise, the same tidal oscillation has been assigned to the east and west sides of the sea rectangle, which correspond to the yellow lines in Figure 3a, but with a time shift of about 20 min, as deduced from preliminary simulations. A wall boundary condition has been applied to all land sides of the mesh, i.e., the white lines, and to the southern seaside. Following Marchi's theoretical approach [35], a uniform Gauckler-Strickler coefficient of $40 \mathrm{~m}^{1 / 3} \mathrm{~s}^{-1}$ has been assumed to represent the bottom roughness both in the tidal channel $\left(K_{s c h}\right)$ and in the basin $\left(K_{s b}\right)$.

Several simulations have been performed starting from this basic configuration, named test 0 , and modifying different parameters regarding both the tidal channel and the lagoon basin. A first series of tests was conducted according to six different configurations of the tidal basin, which have been drawn keeping the longitudinal dimension $W_{b}$ fixed at $10 \mathrm{~km}$ and varying the transversal length $L_{b}$ from a minimum of $2.5 \mathrm{~km}$ to a maximum of $20 \mathrm{~km}$.

The list of related tests is reported in Table 2 . In this way, six lagoon areas $S_{b}$ have been obtained, in order to examine the relationship between the tidal prism and the basin surface, and to clarify the range of values for which Equation (1) can be applied for an assigned tidal inlet. Subsequently, a second set of tests was carried out while changing both basin and inlet channel parameters, according to the list in Table 3. 
Table 2. List of tests performed with the parameters of the basic configuration, named test 0 , and with varying basin sizes. Symbols refer to Figure 3.

\begin{tabular}{cccccccccc}
\hline Test Name & $\boldsymbol{K} \boldsymbol{s}_{\boldsymbol{b}}$ & $\boldsymbol{K} \boldsymbol{s}_{\boldsymbol{c h}}$ & $\boldsymbol{h}_{\boldsymbol{b}}$ & $\boldsymbol{h}_{\boldsymbol{c h}}$ & $\boldsymbol{B}_{\boldsymbol{c h}}$ & $\boldsymbol{A}$ & $\boldsymbol{L}_{\boldsymbol{c h} \boldsymbol{b}}$ & $\mathbf{W}_{\mathbf{b}}$ & $\mathbf{L}_{\mathbf{b}}$ \\
\hline & $\mathbf{m}^{\mathbf{1 / 3}} \mathbf{s}^{-\mathbf{1}}$ & $\mathbf{m}^{\mathbf{1 / 3}} \mathbf{s}^{-\mathbf{1}}$ & $\mathbf{m}$ & $\mathbf{m}$ & $\mathbf{m}$ & $\mathbf{m}^{\mathbf{2}}$ & $\mathbf{K m}$ & $\mathbf{k m}$ & $\mathbf{k m}$ \\
\hline test 0_25 & 40 & 40 & 1.2 & 7 & 250 & 1750 & 2.4 & 10 & 2.5 \\
test 0_50 & 40 & 40 & 1.2 & 7 & 250 & 1750 & 2.4 & 10 & 5.0 \\
test 0_75 & 40 & 40 & 1.2 & 7 & 250 & 1750 & 2.4 & 10 & 7.5 \\
test 0_100 & 40 & 40 & 1.2 & 7 & 250 & 1750 & 2.4 & 10 & 10 \\
test 0_150 & 40 & 40 & 1.2 & 7 & 250 & 1750 & 2.4 & 10 & 15 \\
test 0_200 & 40 & 40 & 1.2 & 7 & 250 & 1750 & 2.4 & 10 & 20 \\
\hline
\end{tabular}

Table 3. List of tests performed with different combinations of both basin and channel parameters. Symbols refer to Figure 3.

\begin{tabular}{|c|c|c|c|c|c|c|c|c|c|c|c|}
\hline Test & $K s_{b}$ & $K s_{c h}$ & $h_{b}$ & $h_{c h}$ & $B_{c h}$ & $A$ & $L_{c h \_b}$ & $\mathrm{~S}_{\mathrm{b}} 25$ & $S_{b} 50$ & $S_{b} 100$ & $S_{b} 200$ \\
\hline Name & $\mathrm{m}^{1 / 3} \mathrm{~s}^{-1}$ & $\mathrm{~m}^{1 / 3} \mathrm{~s}^{-1}$ & $\mathbf{m}$ & $\mathbf{m}$ & m & $\mathrm{m}^{2}$ & $\mathrm{~km}$ & $10 \times 2.5 \mathrm{~km}^{2}$ & $10 \times 5 \mathrm{~km}^{2}$ & $10 \times 10 \mathrm{~km}^{2}$ & $10 \times 20 \mathrm{~km}^{2}$ \\
\hline test 1 & 35 & 35 & 1.2 & 7 & 300 & 1750 & 2.4 & test 1_25 & test 1_50 & test 1_100 & test 1_200 \\
\hline test 2 & 30 & 30 & 1.2 & 7 & 300 & 1750 & 2.4 & test 2_25 & test 2_50 & test 2_100 & test 2_200 \\
\hline test 3 & 25 & 25 & 1.2 & 7 & 300 & 1750 & 2.4 & test 3_25 & test 3_50 & test 3_100 & test 3_200 \\
\hline test 4 & 35 & 40 & 1.2 & 7 & 300 & 1750 & 2.4 & - & test 4_50 & test $4 \_100$ & - \\
\hline test 5 & 30 & 40 & 1.2 & 7 & 300 & 1750 & 2.4 & - & test 5_50 & test 5_100 & - \\
\hline test 6 & 25 & 40 & 1.2 & 7 & 300 & 1750 & 2.4 & - & test 6_50 & test 6_100 & - \\
\hline test 7 & 40 & 40 & 1.2 & 7 & 300 & 1750 & $=L_{b}$ & - & test 7_50 & test 7_100 & - \\
\hline test 8 & 30 & 40 & 1.2 & 7 & 300 & 1750 & $=L_{b}$ & - & test 8_50 & test 8_100 & - \\
\hline test 9 & 25 & 40 & 1.2 & 7 & 300 & 1750 & $=L_{b}$ & - & test 9_50 & test 9_100 & - \\
\hline test 10 & 40 & 40 & 1.2 & 5 & 300 & 1250 & 2.4 & - & test 10_50 & test 10_100 & - \\
\hline test 11 & 40 & 40 & 1.2 & 9 & 300 & 2250 & 2.4 & - & test 11_50 & test 11_100 & - \\
\hline test 12 & 40 & 40 & 1.2 & 11 & 300 & 2750 & 2.4 & - & test $12 \_50$ & test 12_100 & - \\
\hline test 13 & 40 & 40 & 1.2 & 7 & 600 & 3850 & 2.4 & test 13_25 & test 13_50 & test 13_100 & - \\
\hline test 14 & 40 & 40 & 1.2 & 7 & 1000 & 6650 & 2.4 & - & test 14_50 & test 14_100 & test 14_200 \\
\hline test 15 & 40 & 40 & 7 & 7 & 300 & 1750 & 2.4 & - & test 15_50 & test 15_100 & test $15 \_200$ \\
\hline test 16 & 40 & 40 & 7 & 7 & 1000 & 6650 & 2.4 & - & test 16_50 & test 16_100 & test 16_200 \\
\hline
\end{tabular}

In particular, the following parameters have been modified: the Gauckler-Strickler coefficient and the depths of both the basin and the channel; the width and the depth of the inlet and then the corresponding cross-sectional area; the length of the channel entering in the lagoon basin $L_{c h} b$. In some cases, the latter parameter has been assumed to be equal to the entire transverse length of the basin $L_{b}$, in order to understand its influence in the flow propagation within the basin. The configurations of the two basins $S_{b} 50$ and $S_{b} 100$ can be representative of the tidal inlets of Lignano and Malamocco respectively, the latter belonging to the Venice lagoon (see Figure 1b). For these two basins, several combinations of parameters have been adopted in order to check their weight on the prism value and to have a relative comparison.

Finally, in a third simulation phase the computational domain defined by Petti et al. [16] in the previous morphodynamic study on the Lignano inlet, has been used with the aim of estimating the prism in the real case and comparing it with the values obtained by means of the simplified model. For this reason, two configurations have been treated as shown in Figure 4: the former relates to the condition immediately after the construction of the pier, with a larger tidal inlet, whose cross-section is reported in Figure $2 b$, and the bathymetries obtained from the hydrographic map edited in 1964 by the Magistrato alle Acque of Venice [51]; the latter has the bathymetries of the current state. 


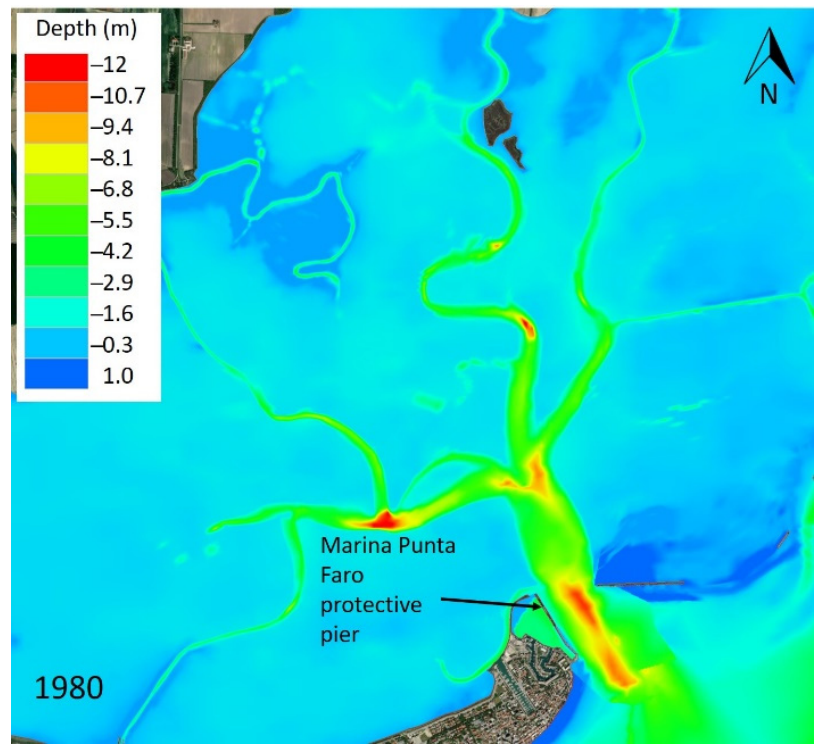

(a)

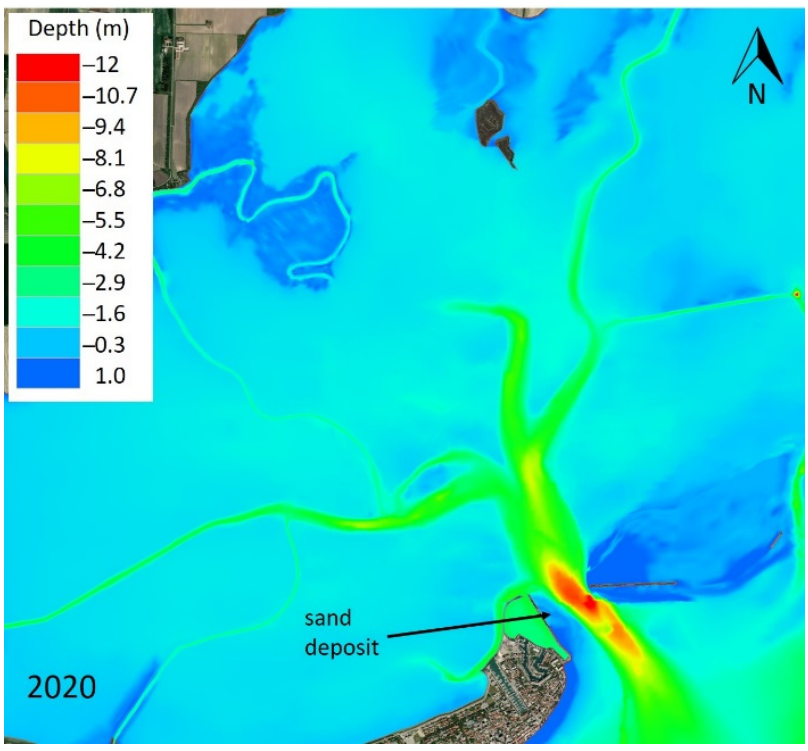

(b)

Figure 4. Details of the computational domains near the Lignano inlet showing the depth in (a) the condition immediately after the construction of the pier and (b) in the current state, in which the sand deposit that has formed over the years is also indicated.

The domain has been discretized with approximately 200,000 quadrangular irregular elements with sides ranging from $0.8 \mathrm{~m}$ to $375 \mathrm{~m}$, and it covers an area that includes a portion of the Marano and Grado lagoon and of the northern Adriatic Sea. The smallest elements have been used to guarantee a more detailed representation of the Lignano inlet area.

In both cases the same sinusoidal tide has been applied for a total time simulation of $48 \mathrm{~h}$ likewise to the previous tests. The tidal prism values have been computed considering the second tidal oscillation, from $24 \mathrm{~h}$ to $48 \mathrm{~h}$, during which the hydrodynamic stability has been achieved in the whole domain.

\section{Results}

For each of the simulations described above, the tidal prism has been calculated integrating the discharge through the regular cross-section of the inlet, over the period of the sinusoidal oscillation. These values have been then compared to those obtained by applying Equation (1) and those computed by means of the 1D static scheme proposed by Marchi [35], which assumes an effectively horizontal free surface in the basin and energy losses distributed only along the channel. In the latter case, the reduction coefficient introduced by Marchi [35] has been considered: in particular, this coefficient has been defined both according to Equation (2) and assuming a rectangular rather than semicircular basin shape.

Finally, a new dynamic reduction coefficient has been introduced, given by the ratio between the tidal prism obtained with the 2D model and that obtained with the 1D static scheme. In the following, the results for the three different groups of tests are reported: the first one considers the variation in the basin transversal length while keeping the geometry of the inlet fixed; the second one identifies different combinations of hydrodynamic parameters concerning both the channel and the basin; the last one presents the simulations performed on the real domain of the Lignano sub-basin.

\subsection{Variation of the Basin Length}

The set of simulations defined in Table 2 has been carried out by means of the 2D model applied to the basic configuration 0 , with the purpose of analyzing the change 
of the tidal prism while keeping the inlet's cross-section size fixed and only varying the transversal length of the lagoon basin. The results are depicted in Figure 5a, where the tidal prism values are plotted as a function of the lagoon basin extension.

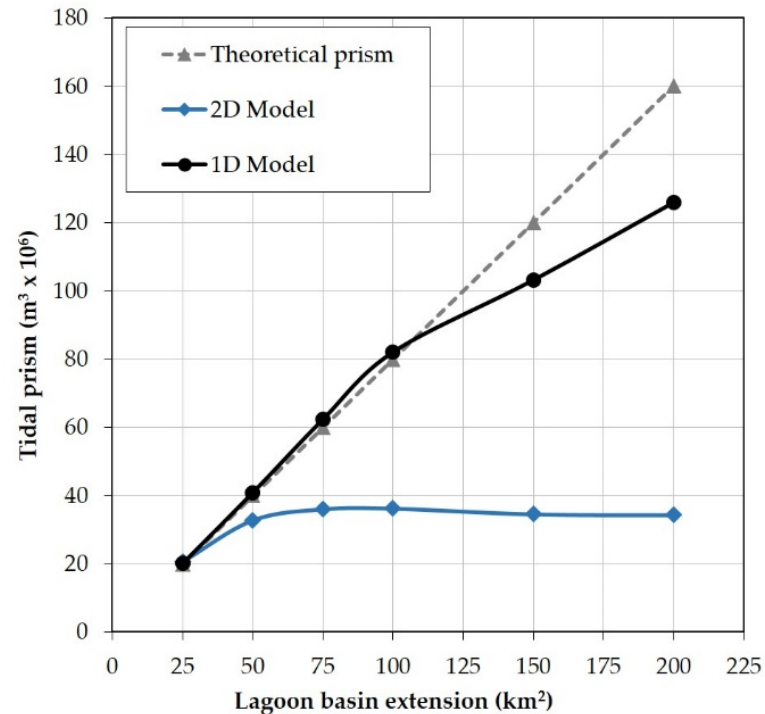

(a)

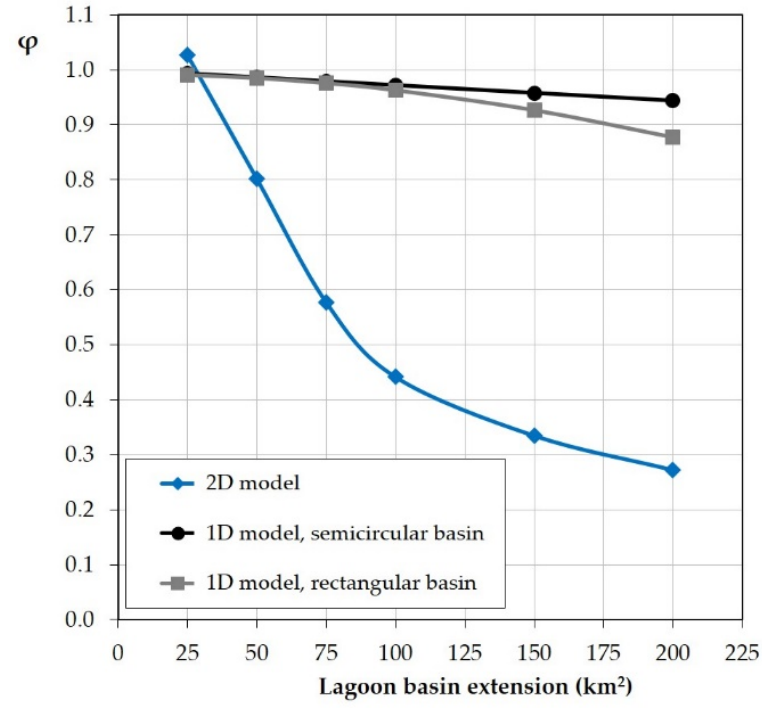

(b)

Figure 5. Curves showing (a) the tidal prism values obtained by varying the surface extension of the lagoon basin, derived from Equation (1) (gray dashed line), the 1D model (black continuous line) and the 2D model (blue continuous line); and (b) the trend of the reduction coefficient calculated with a 1D model considering a semicircular (black continuous line) or rectangular basin (grey continuous line), and the one calculated with the 2D model (blue continuous line).

In particular, three curves are shown in the graph, which compares the prism values derived from the 2D model to those computed by means of the 1D approach and as a first approximation through the Equation (1). As can be observed, there are important differences between the respective values as the basin area increases. The Equation (1) and the 1D model return almost coincident values in the first part of the curves, until the size of the basin becomes important and the effects of the flow propagation cannot be neglected. In fact, even if in a simplified way, the 1D model takes into account the propagation mechanisms through the reduction coefficient, which limits the growth of the prism for greater basin extensions. Figure $5 \mathrm{~b}$ confirms this trend, showing that this coefficient is less than one and it slightly decreases as the transverse length of the basin, and therefore the distance from the inlet, increases.

Instead, the dynamic reduction coefficient, i.e., the blue curve, calculated with the 2D model, is much lower than the previous one. This affects the corresponding curve in Figure $5 \mathrm{a}$ which gives values of the prism that are decidedly lower than the other two and it seems to stabilize on an asymptotic prism value, defined by an almost horizontal trend. This means that the tidal prism cannot grow indefinitely as the area of the basin increases, but it seems to reach a threshold value due to the level differences inside the basin during the propagation.

\subsection{Figures, Tables and Schemes}

The level differences that occur within the lagoon and that are more evident for increasing sizes of the basin, depend on the hydrodynamic characteristics of both the tidal inlet, as the $A-P$ relationship highlights, and the lagoon. In this sense, a sensitivity analysis has been carried out varying some parameters concerning the geometry of both the inlet channel and the basin, and also the bottom friction. For the latter case, in each configuration of Table 2 the Gauckler-Strickler coefficient has been changed uniformly throughout the 
domain, choosing from a range of values comparable to those proposed for both the Venice lagoon [15] and the Marano and Grado lagoon [50].

The corresponding tests are numbers 1,2 and 3 respectively and their results have been depicted in Figure 6, which shows the dependence of the tidal prism not only on the basin surface but also on the bottom friction.

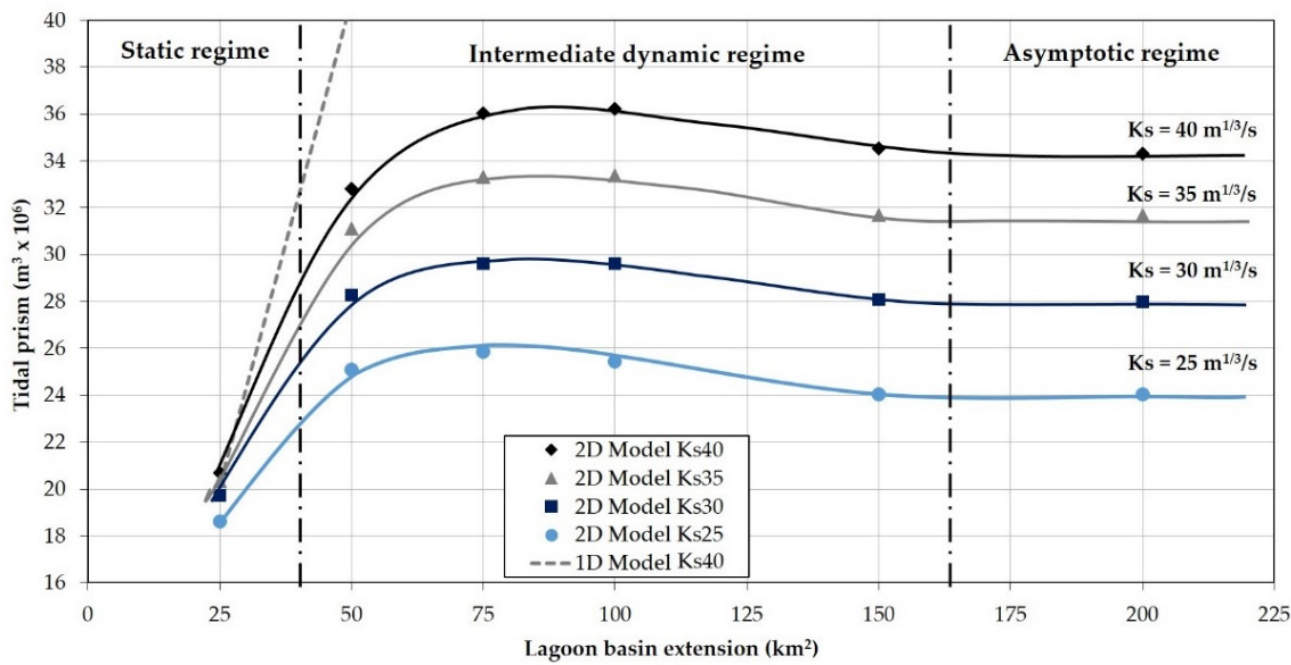

Figure 6. The curves show the trend of the tidal prism from the $2 \mathrm{D}$ model with variations in the extent of the lagoon basin and for different values of the Gauckler-Strickler coefficient of the entire domain. The three different regimes are also highlighted, showing the different behaviors of the relationship between prism and basin extension.

The trend of the curves in the various cases is very similar to the one already seen in Figure 5 a for test 0 , but it is evident that the asymptotic value to which the prism tends, progressively reduces as the conductivity decreases-that is, as the resistance increases. This means that the bottom resistances can play a significant role for the entity of the prism for an assigned value of the basin area, and that as they increase, the difference with the value obtained through the approximate Equation (1) or the 1D model becomes considerable.

In this regard, three different regimes can be distinguished, each corresponding to different parts of the aforementioned curves: the static regime, which coincides with the first rectilinear part, and is characterized by a linear growth of the prism with the lagoon area, as happens in the 1D model; the asymptotic regime for which the prism has reached an upper limit value and it remains almost constant even with greater basin surface values; finally, an intermediate dynamic regime between the two previous ones.

The linear trend is confirmed for small basins, for which the hypothesis of a uniform surface elevation within the lagoon holds, while this is no longer true for the intermediate regime. All the sub-basins of the Marano and Grado lagoon and of the Venice lagoon belong by extension to this intermediate zone $[15,34]$, even if it is necessary to remember that these curves were determined for a precise and fixed geometry of the tidal inlet.

With the aim of verifying which parameters greatly affect the prism in this regime, various configurations have been created, in particular for the two basins with area equal to $50 \mathrm{~km}^{2}$ and $100 \mathrm{~km}^{2}$ respectively. The summary of all the performed tests is reported in Table 4, which specifies the values of the prism obtained with the 2D model and the absolute percentage variation compared to the values derived in the basic configuration or test 0 . 
Table 4. Tidal prism values obtained with the $2 \mathrm{D}$ model for the different tests (referring to Table 3) and the absolute percentage variation of the prism compared to test 0 (whose simulation parameters are given in Table 2).

\begin{tabular}{|c|c|c|c|c|c|c|c|c|}
\hline \multirow{2}{*}{$\begin{array}{c}\text { Test } \\
\text { Name }\end{array}$} & \multicolumn{2}{|c|}{$S_{b} 25$} & \multicolumn{2}{|c|}{$S_{b} 50$} & \multicolumn{2}{|c|}{$S_{b} 100$} & \multicolumn{2}{|c|}{$S_{b} 200$} \\
\hline & $P$ & $|\Delta P| / P_{t e s t 0}$ & $P$ & $|\Delta P| / P_{\text {test0 }}$ & $P$ & $|\Delta P| / P_{\text {test0 }}$ & $P$ & $|\Delta P| / P_{\text {test0 }}$ \\
\hline & $\mathrm{m}^{3} \times 10^{6}$ & $\%$ & $\mathrm{~m}^{3} \times 10^{6}$ & $\%$ & $\mathrm{~m}^{3} \times 10^{6}$ & $\%$ & $\mathrm{~m}^{3} \times 10^{6}$ & $\%$ \\
\hline test 0 & 20.70 & & 32.79 & & 36.23 & & 34.30 & \\
\hline test 1 & 20.08 & 3.0 & 30.92 & 5.7 & 33.00 & 8.9 & 30.84 & 10.1 \\
\hline test 2 & 19.64 & 5.1 & 27.99 & 14.8 & 29.17 & 19.5 & 27.23 & 20.6 \\
\hline test 3 & 18.47 & 10.7 & 25.10 & 23.5 & 24.94 & 31.2 & 23.34 & 32.0 \\
\hline test 4 & - & - & 32.55 & 0.8 & 35.29 & 2.6 & - & - \\
\hline test 5 & - & - & 32.06 & 2.2 & 34.31 & 5.3 & - & - \\
\hline test 6 & - & - & 30.54 & 6.9 & 31.98 & 11.7 & - & - \\
\hline test 7 & - & - & 33.58 & 2.4 & 38.31 & 5.7 & - & - \\
\hline test 8 & - & - & 33.12 & 1.0 & 37.09 & 2.4 & - & - \\
\hline test 9 & - & - & 31.51 & 3.9 & 35.98 & 0.7 & - & - \\
\hline test 10 & - & - & 24.04 & 26.7 & 25.28 & 30.2 & - & - \\
\hline test 11 & - & - & 37.75 & 15.1 & 43.15 & 19.1 & - & - \\
\hline test 12 & - & - & 40.44 & 23.3 & 50.23 & 38.7 & - & - \\
\hline test 13 & 20.89 & 0.9 & 41.39 & 26.2 & 55.44 & 53.0 & - & - \\
\hline test 14 & - & - & 41.98 & 28.0 & 65.94 & 82.0 & 61.40 & 79.0 \\
\hline test 15 & - & - & 35.28 & 7.6 & 36.36 & 0.4 & 41.57 & 21.2 \\
\hline test 16 & - & - & 42.32 & 29.1 & 86.31 & 138.2 & 139.99 & 308.2 \\
\hline
\end{tabular}

In tests 4,5 and 6 a further aspect concerning the bed resistances has been investigated, in particular the relative importance of the bottom friction inside the channel and the friction inside the basin, on tidal or subtidal flats. These tests, compared to the preceding tests 1, 2 and 3 consider different values of the Gauckler-Strickler coefficient for the channel and for the lagoon, since generally the tidal flats can be characterized by vegetation or bedforms [50]. The results and the comparison are depicted in Figure 7.

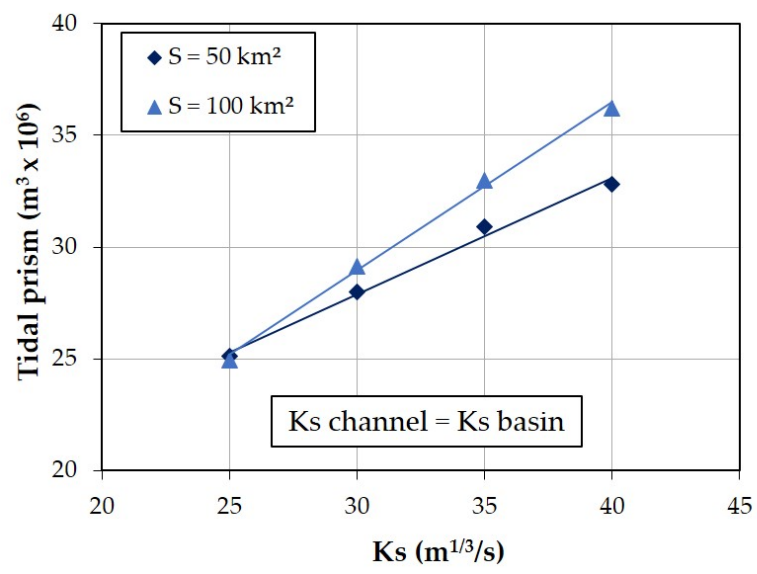

(a)

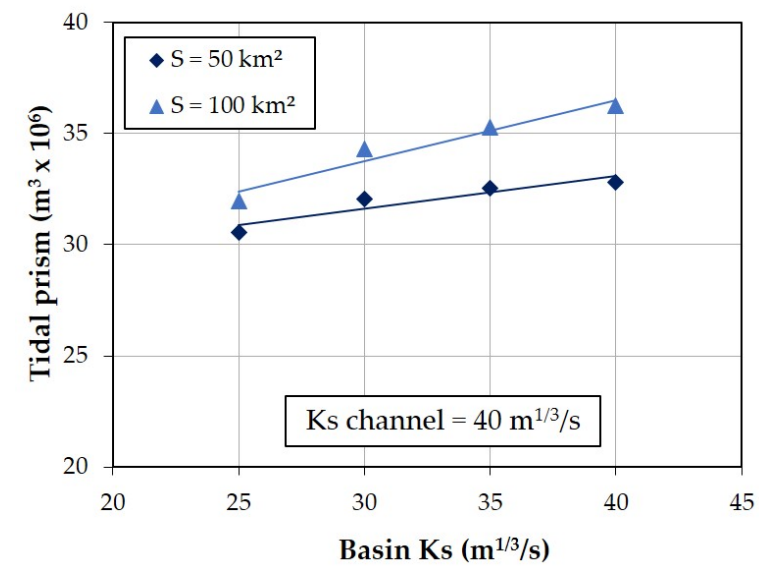

(b)

Figure 7. 2D tidal prism for lagoon basins equal to $50 \mathrm{~km}^{2}$ (dark blue) and $100 \mathrm{~km}^{2}$ (light blue) with (a) a uniform value of the Gauckler-Strickler coefficient in the entire domain, or (b) with different coefficients for the channel and the basin.

The reduction of the prism due to bottom friction dissipations is greater when the Gauckler-Strickler coefficient is lower both in the channel and in the basin, with a variation from the initial value up to $30 \%$ as shown in Table 4 . On the other hand, when the conductivity is reduced only within the basin, then the reduction of the prism is more limited and it reaches a percentage of $5-10 \%$. This underlines the importance, from a hydrodynamic point of view, of the channel that enters the basin as it strongly conveys the flow and therefore the water volume exchanged with the sea. 
However, the role played by the channel in allowing propagation within the basin seems to weakly depend on its length. In tests 7,8 and 9 the length of the internal channel has been set as equal to the entire transverse length of the basin, in order to verify whether the prism increases despite the greater resistances on the flats. Comparing the results in these configurations with the analogous ones having the length $L_{c h} b$ equal to $2.4 \mathrm{~km}$, i.e., tests 0,5 and 6 respectively, the increase of the prism is on average equal to $3 \%$ for the basin of $50 \mathrm{~km}^{2}$ while it is close to $9 \%$ for that of $100 \mathrm{~km}^{2}$.

The role of the main channel in the tidal flow propagation had already emerged from the previous analyses that led several authors to search for a relationship between the prism and the tidal inlet cross-section characteristics, neglecting what happens inside the basin. In light of this, other configurations have been realized in which the geometric dimensions of the tidal inlet and the channel have been varied to better understand the effects on the prism. In tests 10-14, the inlet depth or width, and consequently the cross-sectional area, have been changed.

Figure 8a presents these results, showing that the width of the channel greatly affects the prism, which tends to increase monotonically up to a maximum value which corresponds to the limit threshold for the assigned basin surface, provided by the 1D model.

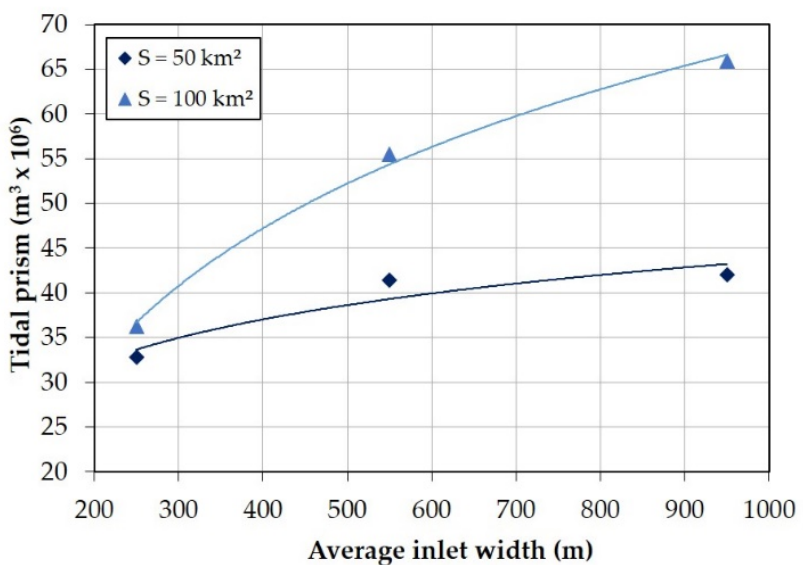

(a)

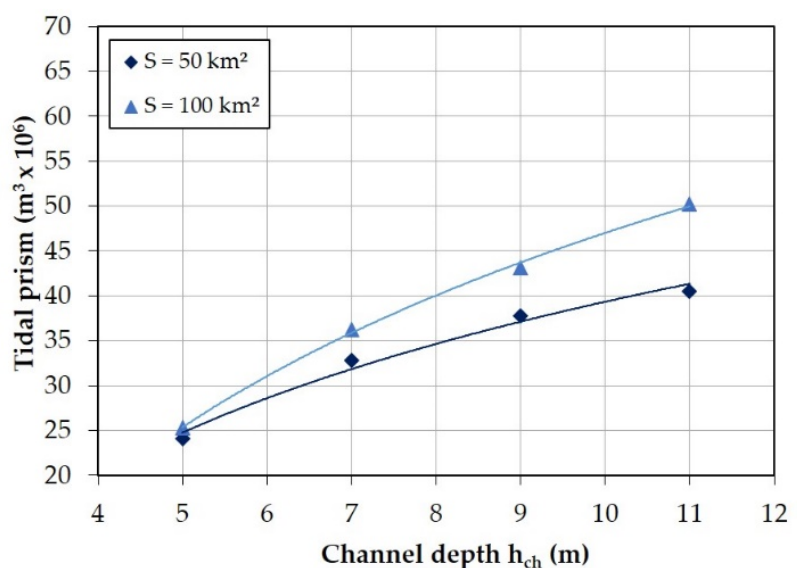

(b)

Figure 8. Trend of tidal prism from the 2D model for lagoon basins of $50 \mathrm{~km}^{2}$ (dark blue) and $100 \mathrm{~km}^{2}$ (light blue) with (a) variation of the average inlet width and (b) of the channel depth $h_{c h}$.

In this case and for the width values assumed, the percentage variations of the prism compared to the basic configuration are decidedly high, around $26-28 \%$ for $\mathrm{S}_{\mathrm{b}} 50$ and $53-82 \%$ for $S_{b} 100$. The depth of the channel also affects the prism, although to a lesser extent than the width, especially for the $S_{b} 100$ basin. The percentage variations however reach the absolute maximum values in the two configurations of about $26 \%$ and $38 \%$ respectively.

The depth of the basin also affects the prism value and this has been verified with the last two tests 15 and 16. In this sense, a flattening of the basin is assumed such that its depth is equal to the channel depth; in the first case, i.e., test 15, the width of the inlet is the same as the basic configuration and the prism increases slightly both in the $S_{b} 50$ and the $\mathrm{S}_{\mathrm{b}} 100$ domain; on the contrary, the increase is considerable if the inlet is greatly enlarged as hypothesized in test 16 . In the latter case the final values are close to those computed by the 1 D model, i.e., approximately $41 \times 10^{6} \mathrm{~m}^{3}$ and $82 \times 10^{6} \mathrm{~m}^{3}$ for the two configurations respectively.

\subsection{Comparison with the Real Domain of the Lignano Sub-Basin}

Finally, it remains to explain why in the case of the Lignano tidal inlet, the progressive reduction of the cross-section width did not lead to a substantial variation of the prism [16]. This seems to disagree with the results of Figure 8a, which shows instead 
that by approximately halving the average section width, as occurred in the narrowing trend of the Lignano inlet, the prism decreases by $26 \%$ in the $S_{b} 50$ configuration. In this regard, simulations have been performed on the computational domain of the real basin of Lignano, both in the current configuration and the one immediately after the construction of the pier, as described in Section 3. In order to compare the values obtained on the real mesh with those on the simplified domain, the area of the inlet section and the channel depth have been made as close as possible to the two real configurations, maintaining both the trapezoidal section and the straight channel. Furthermore, an equivalent value of $k_{s}$ has been calculated, weighted on the areas with different bed roughness defined on the real domain as in the previous studies of Petti et al. [16,50]. The equivalent GaucklerStrickler coefficient is approximately $33 \mathrm{~m}^{1 / 3} \mathrm{~s}^{-1}$, and it has been assigned uniformly on the schematic basin. The results are reported in Table 5 , together with the absolute percentage variation of the prism compared to the year 1980.

Table 5. Tidal prism values obtained with the $2 \mathrm{D}$ model used on the schematic basin and the real Lignano sub-basin with the configurations related to the two reported years and the absolute percentage variation of the prism compared to 1980.

\begin{tabular}{cccccc}
\hline Year & $\begin{array}{c}A \\
\left(\mathbf{m}^{\mathbf{2}}\right)\end{array}$ & $\boldsymbol{P}\left(\mathbf{m}^{\mathbf{3}} \times \mathbf{1 0}^{\mathbf{6}}\right)$ & $\mathbf{I} \boldsymbol{\Delta} \boldsymbol{P} \mid / \boldsymbol{P}_{\mathbf{1 9 8 0}}(\mathbf{\%})$ & $\boldsymbol{P}\left(\mathbf{m}^{\mathbf{3}} \times \mathbf{1 0}^{\mathbf{6}}\right)$ & $\mathbf{I} \boldsymbol{\Delta} \boldsymbol{P} \mid / \boldsymbol{P}_{\mathbf{1 9 8 0}}(\mathbf{\%})$ \\
\hline 1980 & 3300 & 36.4 & & 33.4 & \\
2020 & 2750 & 33.9 & 6.9 & 35.0 & 4.7 \\
\hline
\end{tabular}

The comparison confirms that the variation of the prism between the two configurations, both on the schematic and real domain, is small and on average equal to $5.8 \%$. To understand how this relates to the results previously determined and described in Section 4.2, a further graph has been plotted based on the performed tests. Figure 9 shows the main results obtained in the tests of Tables 3 and 4 as a function of the inlet crosssectional area, both for the $S_{b} 50$ and $S_{b} 100$ configuration. For homogeneity, the cases computed with uniform $\mathrm{Ks}$ equal to $40 \mathrm{~m}^{1 / 3} \mathrm{~s}^{-1}$ have been considered.

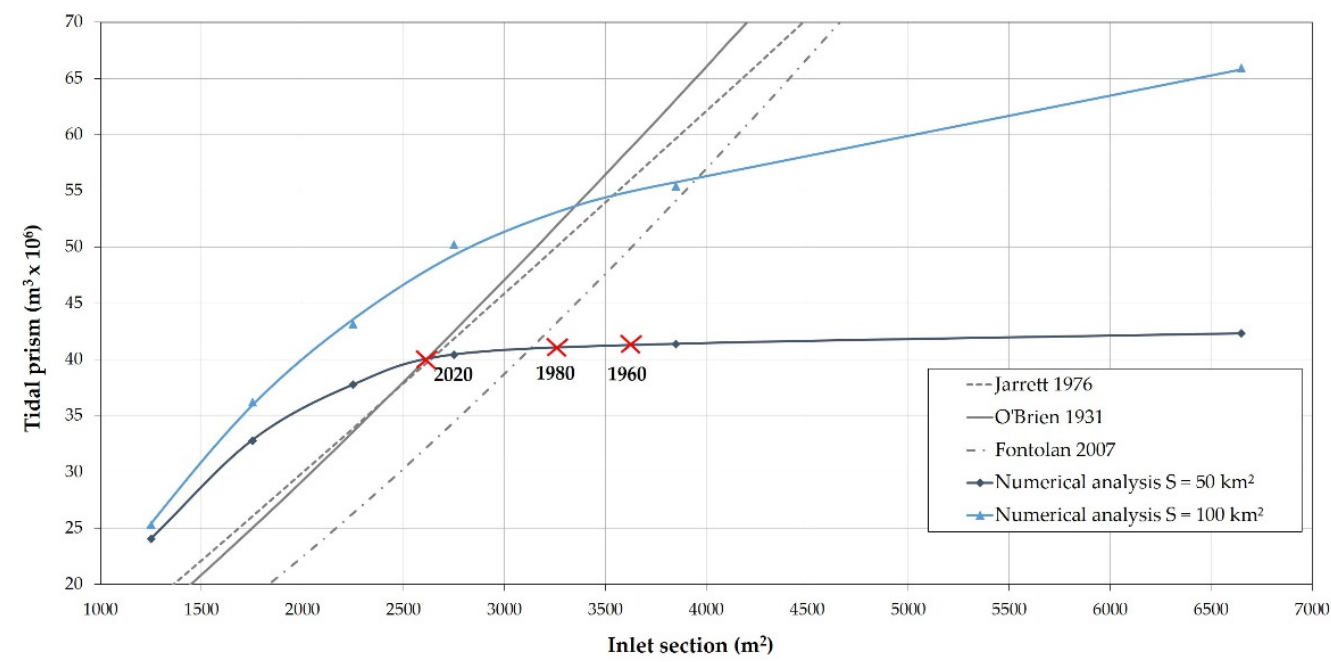

Figure 9. Tidal prism trend from 2D model for $50 \mathrm{~km}^{2}$ (dark blue) and $100 \mathrm{~km}^{2}$ (light blue) lagoon basin extensions, as a function of the inlet cross-section area. The three red crosses correspond to the values of the prism for the Lignano inlet in three different years. The grey curves are the $A-P$ relationships specified in the legend and the parameters reported in Table 1.

The determined curves, dark blue for the $\mathrm{S}_{\mathrm{b}} 50$ and light blue for the $\mathrm{S}_{\mathrm{b}} 100$ respectively, are characterized by an initial linear trend and then they tend to an asymptotic value, more evident for the $S_{b} 50$ case, probably close to the value provided by the $1 \mathrm{D}$ model, 
as discussed above. The three red crosses, taken on the dark blue curve, correspond to the prism values that would occur for three cross-sectional areas of the Lignano inlet, as happened in three different years: in 1960, with the natural configuration before the port was built; in 1980 immediately after its construction and finally in 2020 with the sand deposit behind the pier and the current narrowing of the inlet. Both the 1960 and 2020 configurations can be considered close to an equilibrium condition, as suggested by Petti et al. [16]. In particular, the position of the three red crosses on the curve actually indicates that the prism differs slightly between the relative configurations, this part of the curve being almost horizontal. The current condition, seems to be a limit value, such that a further narrowing would lead to a more important reduction of the prism.

Furthermore, this point is located on the intersection of the curve with the $A-P$ relationships obtained by $\mathrm{O}^{\prime}$ Brien $[20,21]$ and Jarrett [22], with the parameters specified in Table 1. This would also confirm that the current cross-section of the Lignano inlet is in equilibrium for the given tidal prism, also from an experimental point of view. The relationship derived by Fontolan et al. [34] provides an equilibrium value for the inlet section close to the one of 1980. In fact, the coefficients $k$ and $\alpha$ of Equation (3) are relative to the inlet morphological condition similar to the 2006 one plotted in Figure 2a, in which the deposit has not yet affected the entire area close to the pier but only a small portion, making this configuration similar to the 1980 one, immediately after the construction of the port.

\section{Discussion}

The water exchange between the sea and the lagoon has been analyzed in this study by means of a conceptual scheme, which considers two basins connected by a straight channel. This simplified representation of the sea-channel-lagoon system has been used by other authors both to determine an analytical relationship between the prism and the inlet characteristics [35], and to perform numerical simulations with low computational costs $[15,36]$. In the present study, a sensitivity analysis has been conducted on this scheme in order to understand which geometric and hydrodynamic parameters affect the value of the tidal prism, i.e., the volume that crosses the inlet during a tidal cycle. In fact, analysis and experimental testing carried out on the Lignano tidal inlet have shown that, despite a considerable reduction in the width of the section, the prism has remained substantially unchanged [16]. This result does not seem to agree with the $A-P$ relationship (3), which links the equilibrium section to the tidal prism, since both the two conditions, ante-operam and current one, can be considered morphologically stable [16].

Several tests have been carried out to understand the relative role of the basin sizes, of the inlet cross-sectional area, but above all of the resistances distributed within the basin, here represented by the bottom friction dissipations. The tidal prism has been calculated both as an integral of the flow rates over time by means of the 2D hydrodynamic model, and with the static model, the latter in its simplified form given by Equation (1) or through the Marchi 1D approach [35]. The static model is inspired by the principle of communicating vessels for which the surface elevation is uniform inside each tank. In the case of the sea-channel-lagoon system, the level oscillations in the sea basin are transferred as level variations in the lagoon basin. If the time of the flow propagation is not taken into account and the surface elevation is assumed uniform everywhere, then the tidal prism can effectively be expressed as the product of the tidal excursion and the basin surface. Marchi [35] introduced the resistance along the channel and the reduction coefficient which considers level differences inside the lagoon due to the distance from the inlet.

The simulations of test 0 for different lagoon sizes show that the 2D model provides very different results compared to the $1 \mathrm{D}$ model as the basin area increases. When keeping the geometry of the inlet fixed, the two methods give comparable prism values for small lagoon dimensions, for which the hypothesis of uniformity of levels can really be considered satisfied. A similar result was pointed out by Reef et al. [36] who recognized a linear regime in the link between the prism and the lagoon transverse length for narrow basins compared 
to the tidal wavelength. The dimensions of the basins that have been reproduced in the tests of this study are all such as to meet this condition, however the linear trend is confirmed only in a limited part of the curves depicted in Figure 6, defined as static regime. In this first asymptotic condition the prism depends only on the surface of the basin and is also affected, to a very limited extent, by the bed roughness in the channel which determines the energy losses along it. On the other hand, it is independent from the inlet geometry, since by widening or deepening the cross-section the prism does not substantially change.

There is a second asymptotic regime for which the prism does not grow indefinitely as the size of the lagoon increases, but it reaches a limit value that varies according to the bed roughness of the basin. This outcome is very important, as it highlights the decisive role played by energy losses inside the basin, which cannot be neglected in the prism evaluation, since the flow propagation depends on the consequent level differences within the lagoon. Bottom friction had not yet been considered among the parameters influencing the prism, with the exception of Reef et al. [36], who demonstrated that strong roughness can completely dissipate the tidal wave in wide basins.

The central part of the curves in Figure 6, which connects the two limit regimes, defines a transition zone in which the value of the prism depends, for a given inlet cross-section, on both parameters: the width of the basin and its roughness. The second part of the work therefore concentrated on the study of the configurations that belong to this intermediate regime, in particular the two basin extensions of $50 \mathrm{~km}^{2}$ and $100 \mathrm{~km}^{2}$ respectively. In particular, the analysis of the results reveals that the asymptotic tendency of the prism to approach the value provided by the $1 \mathrm{D}$ model also occurs when the geometry of the cross-section is modified, keeping the basin dimensions constant. Specifically, it can be seen that, by enlarging the inlet section, the prism can grow considerably. In fact, if the width is assumed as equal to the basin longitudinal length, then the contemporaneity of the levels inside the lagoon would be more easily reached and for this reason the prism tends to the value determined by means of the static approach.

Similarly, this happens even if the basin deepens, because the energy losses due to friction dissipations are a function of the current velocities, which decrease for lower water depth and if the discharge is approximately the same. This effect is however bound to the width of the cross-section, as if the shrinking of the inlet still has a greater weight on the amount of water that can be exchanged with the sea. In this sense, the fundamental role played by the main channel in the propagation of the tidal wave inside the basin is confirmed, with consequences from both a hydrodynamic and an environmental point of view. This also emerges when different Gauckler-Strickler coefficients are assigned to the basin and the channel respectively, resulting in the variations on the prism being more relevant when the roughness of the channel also changes. In any case, the tests carried out confirm the need to also consider what belongs to the basin in the calculation of the prism, both in geometric and dissipative terms.

The link between the tidal prism and the inlet cross-sectional area is undoubtedly dominant, and this is nothing new compared to the well-known $A-P$ relationship. The novelty of the results derived from this study lies in the asymptotic trend of this link, as shown by the graph of Figure 9, for which there can be infinite values of the inlet area that could be morphologically stable for the same prism. This explains why the tidal prism of the Lignano sub-basin has not changed in the last forty years while the inlet has halved. A prism variation of the order of only $5 \%$ between the 1980 configuration and the present one has been determined by applying the $2 \mathrm{D}$ model to the real computational domains. These tests are in agreement with those performed on the simplified scheme which is therefore validated in its representativeness of the sea- channel-lagoon system.

The $A-P$ empirical relationships proposed by O'Brien [20,21], Jarrett [22] and Fontolan et al. [34] have been superimposed on the curve determined for the $S_{b} 50$ configuration. The first two intersect exactly at the current section of the inlet, i.e., the 2020 red cross, suggesting that this is the minimum area of equilibrium and further confirming the results from the previous study by Petti et al. [16]. However, there is an important new aspect: if 
the narrowing trend continues, even due to artificial interventions on the inlet, the prism would be reduced, affecting the hydrodynamic and environmental balance of the entire lagoon in this manner.

In light of this, the present study can be considered a first step to understanding the fundamental aspects of the link between the prism and the different geometric and hydrodynamic factors of the inlet and the lagoon basin. Furthermore, the evidence that emerged can be the basis for subsequent reasoning on the management and maintenance interventions of the hydraulic functionality of the tidal inlets.

\section{Conclusions}

The focus of the paper was to analyze the relationships between the tidal prism and the geometric and hydrodynamic factors that characterize both the inlet and the lagoon basin. The study has been carried out by means of an idealized scheme with a simplified geometry, with characteristics typical of the northern Adriatic Sea lagoons. The factors considered in the analysis were the following: lagoon basin extension; size of the tidal inlet; depth and length of the tidal channel; and the bottom roughness inside both the channel and the lagoon basin. A 2D hydrodynamic model has been applied to evaluate the tidal prism, which has been compared to that derived by a static model. Three different regimes of prism behavior as a function of both basin extension and bottom friction have been identified, for an assigned inlet geometry. The basin configurations belonging to the intermediate dynamic regime have been analyzed, confirming the central role covered by the tidal channel characteristics that allows the propagation of the flow within the basin. The $A-P$ relationship can provide a very different equilibrium inlet area according to the variability of its empirical parameters, but this study has shown that the prism tends toward an asymptotic value as the inlet area increases. In this sense, there is no single equilibrium condition for the inlet section, but in some cases a variation in the inlet cross-sectional area can induce significant prism modification. This is the case for the Lignano inlet, in which a narrowing trend occurring in the last forty years did not change the prism, suggesting the achievement of a new morphologically stable condition. However, the current situation could be a lower limit, in the sense that a further section narrowing could lead to a reduction in the prism value, which could then greatly affect the entire lagoon environment.

Author Contributions: M.P., S.P., S.B. and N.B. contributed equally to this work in all its stages: conceptualization, methodology, data curation, formal analyses, writing, review and editing. All authors have read and agreed to the published version of the manuscript.

Funding: This research received no external funding.

Institutional Review Board Statement: Not applicable.

Informed Consent Statement: Not applicable.

Data Availability Statement: Data is contained within the article.

Conflicts of Interest: The authors declare no conflict of interest.

\section{References}

1. Schwartz, M. Coastal Lakes and Lagoons. In Encyclopedia of Coastal Science, 1st ed.; Springer: Dordrecht, The Netherlands, 2005; Volume 1, pp. 263-264.

2. Sassi, M.; Matute, M.M.D.; Van Kessel, T.; Gerkema, T. Variability of residual fluxes of suspended sediment in a multiple tidal-inlet system: The Dutch Wadden Sea. Ocean Dyn. 2015, 65, 1321-1333. [CrossRef]

3. Petti, M.; Pascolo, S.; Bosa, S.; Uliana, E.; Faggiani, M. Sea defences design in the vicinity of a river mouth: The case study of Lignano Riviera and Pineta. IOP Conf. Ser. Mater. Sci. Eng. 2019, 603, 032067. [CrossRef]

4. Petti, M.; Bosa, S.; Pascolo, S.; Uliana, E. Marano and Grado Lagoon: Narrowing of the Lignano Inlet. IOP Conf. Ser. Mater. Sci. Eng. 2019, 603, 032066. [CrossRef]

5. Petti, M.; Pascolo, S.; Bosa, S.; Bezzi, A.; Fontolan, G. Tidal Flats Morphodynamics: A new Conceptual Model to Predict Their Evolution over a Medium-Long Period. Water 2019, 11, 1176. [CrossRef] 
6. Pascolo, S.; Petti, M.; Bosa, S. Wave Forecasting in Shallow Water: A New Set of Growth Curves Depending on Bed Roughness. Water 2019, 11, 2313. [CrossRef]

7. Hayes, M.O.; Fitzgerald, D.M. Origin, Evolution, and Classification of Tidal Inlets. J. Coast. Res. 2013, 69, 14-33. [CrossRef]

8. Vu, T.T.; Nielsen, P.; Callaghan, D. Morphology of coastal lagoon entrances: Waves versus tides. Coast. Eng. Proc. 2014, 1, 89. [CrossRef]

9. Michel, D.; Howa, H. Morphodynamic behaviour of a tidal inlet system in a mixed-energy environment. Phys. Chem. Earth 1997, 22, 339-343. [CrossRef]

10. Mulhern, J.S.; Johnson, C.L.; Martin, J.M. Is barrier island morphology a function of tidal and wave regime? Mar. Geol. 2017, 387, 74-84. [CrossRef]

11. De Swart, H.; Zimmerman, J. Morphodynamics of Tidal Inlet Systems. Annu. Rev. Fluid Mech. 2009, 41, 203-229. [CrossRef]

12. Byrne, R.J.; Gammisch, R.A.; Thomas, G.R. Tidal Prism-Inlet Area Relations for Small Tidal Inlets. In Proceedings of the 17th International Conference on Coastal Engineering, Sydney, Australia, 23-28 March 1980. Chapter 151.

13. D'Alpaos, A.; Lanzoni, S.; Marani, M.; Rinaldo, A. On the tidal prism-channel area relations. J. Geophys. Res. Space Phys. 2010, 115, 01003. [CrossRef]

14. Jacob, J.; Cravo, A. Recent evolution of the tidal prisms at the inlets of the western sector of the Ria Formosa, south coast of Portugal. Reg. Stud. Mar. Sci. 2019, 31, 100767. [CrossRef]

15. Tambroni, N.; Seminara, G. Are inlets responsible for the morphological degradation of Venice Lagoon? J. Geophys. Res. Space Phys. 2006, 111. [CrossRef]

16. Petti, M.; Bosa, S.; Pascolo, S.; Uliana, E. An Integrated Approach to Study the Morphodynamics of the Lignano Tidal Inlet. J. Mar. Sci. Eng. 2020, 8, 77. [CrossRef]

17. Marani, M.; Belluco, E.; D’Alpaos, A.; Defina, A.; Lanzoni, S.; Rinaldo, A. On the drainage density of tidal networks. Water Resour Res. 2003, 39, 1040. [CrossRef]

18. Wang, H.; Chen, P.M.; Jia, X.P.; Zhang, S.; Tang, Z.; Yu, J.; Tao, F. Advance in the research on water exchange in the sea area. South China Fish. Sci. 2008, 4, 75-80. (In Chinese)

19. D'Alpaos, A.; Lanzoni, S.; Marani, M.; Rinaldo, A. On the O’Brien-Jarrett-Marchi law. Rend. Lince. 2009, 20, 225-236. [CrossRef]

20. O'Brien, M.P. Estuary Tidal Prism Related to Entrance Areas. Civil Eng. 1931, 1, 8.

21. O'Brien, M.P. Equilibrium flow areas of tidal inlets on sandy coasts. Coast. Eng. Proc. 1966, 1, 38. [CrossRef]

22. Jarrett, J.T. Tidal Prism - Inlet Area Relationships; GITI report no. 3; Coastal Engineering Research Center, US Army Corps of Engineers: Fort Belvoir, VA, USA, 1976.

23. Le Conte, L.J. Discussion on the Paper, Notes on the Improvement of River and Harbor Outlets in the United State; ASCE: Reston, VA, USA, 1905; pp. 306-308.

24. Escoffier, F.F. The Stability of Tidal Inlets. Shore Beach. 1940, 8, 114-115.

25. Furkert, F.W. Tidal compartments, their influence on dimensions of harbour entrance channels. Proc. N. Z. Inst. Eng. 1947, 33, 195-211.

26. Heath, R.A. Stability of some New Zealand coastal inlets. N. Z. J. Mar. Freshw. Res. 1975, 9, 449-457. [CrossRef]

27. Krishnamurthy, M. Tidal prism of equilibrium inlets. J. Waterw. Port Coast. Ocean. Div. 1977, 103, 423-432.

28. Bruun, P. Stability of Tidal Inlet, 1st ed.; Elsevier Scientific Publishing Company: Amsterdam, The Netherlands, 1978.

29. Shigemura, T. Tidal prism-throat area relationships of the bays of Japan. Shore Beach 1980, 48, 30-35.

30. Hume, T.M.; Herdendorf, C.E. The “Furkert-Heath" relationship for tidal inlet stability reviewed. N. Z. J. Mar. Freshw. Res. 1988, 22, 129-134. [CrossRef]

31. Friedrichs, C.T. Stability shear stress and equilibrium cross-sectional geometry of sheltered tidal channels. J. Coast. Res. 1995, 11, 1062-1074.

32. Hughes, S.A. Equilibrium cross-sectional area at tidal inlets. J. Coast. Res. 2002, 18, 160-174.

33. Di Silvio, G.; Dal Monte, L. Ratio between channel cross section and tidal prism in short lagoons: Validity and limits of the Law of Jarrett. In Proceedings of the 3rd IAHR Symposium on River, Coastal and Estuarine Morphodynamics, Barcelona, Spain, 1-5 September 2003; pp. 524-533.

34. Fontolan, G.; Pillon, S.; Quadri, F.D.; Bezzi, A. Sediment storage at tidal inlets in northern Adriatic lagoons: Ebb-tidal delta morphodynamics, conservation and sand use strategies. Estuar. Coast. Shelf Sci. 2007, 75, 261-277. [CrossRef]

35. Marchi, E. Sulla stabilità delle bocche lagunari a marea. Rend. Lincei. 1990, 9, 137-150. (In Italian) [CrossRef]

36. Reef, K.R.G.; Roos, P.C.; Schuttelaars, H.M.; Hulscher, S.J.M.H. Influence of Back-Barrier Basin Geometry on Multiple Tidal Inlet Systems: The Roles of Resonance and Bottom Friction. J. Geophys. Res. Earth Surf. 2020, 125, e2019JF005261. [CrossRef]

37. Seabergh, W.C. Hydrodynamics of Tidal Inlets. In Coastal and Hydraulics Laboratory, Engineer Research and Development Center; Springer: Vicksburg, MS, USA, 2002.

38. Dronkers, J.J. Tidal Computations in Rivers and Coastal Waters; North-Holland Pub. Co.: Amsterdam, The Netherlands; Interscience Publishers: New York, NY, USA, 1964.

39. Rinaldo, A.; Fagherazzi, S.; Lanzoni, S.; Marani, M.; Dietrich, W.E. Tidal networks: 3. Landscape-forming discharges and studies in empirical geomorphic relationships. Water Resour. Res. 1999, 35, 3919-3929. [CrossRef]

40. Fang, S.; Xie, Y.; Cui, L. Analysis of Tidal Prism Evolution and Characteristics of the Lingdingyang Bay at Pearl River Estuary. MATEC Web Conf. 2015, 25, 01006. [CrossRef] 
41. Umgiesser, G.; Helsby, R.; Amos, C.L.; Ferrarin, C. Tidal Prism Variation in Venice Lagoon and Inlet Response over the Last 70 Years. In Coastal World Heritage Sites; Springer Science and Business Media LLC: Berlin/Heidelberg, Germany, 2014; Volume 10, pp. 151-165.

42. Silva, R.A.G.; Gallo, M.N.; Rosman, P.C.C.; Nogueira, I.C.M. Tidal inlet short-term morphodynamics analysed trough the tidal prism-longshore sediment transport ratio criterion. Geomorphology 2020, 351, 106918. [CrossRef]

43. Mayor-Mora, R.E. Laboratory Investigation of Tidal Inlets on Sandy Coasts; GITI Report 11; US Army Engineer Waterways Experiment Station: Vicksburg, MS, USA, 1977.

44. Stive, M.J.F.; Van De Kreeke, J.; Lam, N.T.; Tung, T.T.; Ranasinghe, R.; Mizuguchi, M.; Sato, S. Empirical relationships between inlet cross-section and tidal prism: A review. In Proceedings of the Coastal Dynamics, Tokyo, Japan, 7-11 September 2009; pp. $1-10$.

45. Kraus, N.C. Inlet Cross-Sectional Area Calculated by Process-Based Model. In Proceedings of the Coastal Engineering, Copenhagen, Denmark, 22-26 June 1998; Volume 3, pp. 3265-3278.

46. Carniello, L.; Defina, A.; D'Alpaos, L. Morphological evolution of the Venice lagoon: Evidence from the past and trend for the future. J. Geophys. Res. Space Phys. 2009, 114. [CrossRef]

47. Helsby, R.; Amos, C.L.; Umgiesser, G. Tidal Prism Variation and Associated Channel Stability. In Proceedings of Corila Research Programme 2004-2006; Lagoon, N.V., Campostrini, P., Eds.; Scientific Research and Safeguarding of Venice: Venice, Italy, 2008; Volume VI, pp. 453-466.

48. Sarretta, A.; Pillon, S.; Molinaroli, E.; Guerzoni, S.; Fontolan, G. Sediment budget in the Lagoon of Venice, Italy. Cont. Shelf Res. 2010, 30, 934-949. [CrossRef]

49. Fontolan, G.; Pillon, S.; Bezzi, A.; Villalta, R.; Lipizer, M.; Triches, A.; D'Aietti, A. Human impact and the historical transformation of saltmarshes in the Marano and Grado Lagoon, northern Adriatic Sea. Estuar. Coast. Shelf Sci. 2012, 113, 41-56. [CrossRef]

50. Petti, M.; Bosa, S.; Pascolo, S. Lagoon Sediment Dynamics: A Coupled Model to Study a Medium-Term Silting of Tidal Channels. Water 2018, 10, 569. [CrossRef]

51. Dorigo, L. La Carta Idrografica Della Laguna di Grado e Marano. Magistrato Alle Acque; Ufficio Idrografico: Venice, Italy, 1966.

52. Dorigo, L. La Laguna di Grado e le Sue Foci. Ricerche e Rilievi Idrografici. Magistrato Alle Acque; Ufficio Idrografico: Venice, Italy, 1965.

53. Bosa, S.; Petti, M.; Pascolo, S. Numerical Modelling of Cohesive Bank Migration. Water 2018, 10, 961. [CrossRef] 